\title{
Time-effect of penile color duplex Doppler ultrasound for diagnosing vascular erectile dysfunction
}

\author{
Jin Wang ${ }^{1 *}$, Jing Wang ${ }^{2 *}$, Qian Liu ${ }^{1,3}$, Huijun Jia², Cuihong Zhang², Cong Liu², Lin Sun', \\ Dong Shu', Jiugao Xia ${ }^{1}$, Jialun Guo ${ }^{1}$, Yanli Wang', Yong Tang ${ }^{1}$, Yali Yang ${ }^{2}$, Zhaohui Zhu' \\ * The authors shared the first authorship
}

${ }^{1}$ Department of Urology, ${ }^{2}$ Department of Ultrasound, ${ }^{3}$ Department of Nosocomial Infection Management, Union Hospital, Tongji Medical College, Huazhong University of Science and Technology, Wuhan, China

\begin{abstract}
Introduction: This study aimed to explore the time-effect of color duplex Doppler ultrasound (CDDU) in the diagnosis of vascular erectile dysfunction (ED). Material and methods: Using a self-control study, we included patients who underwent penile CDDU and cavernosography in our hospital. We compared the arterial peak systolic velocity (PSV) of CDDU among different intervals for the diagnosis of arterial ED. We included 357 patients who were under consideration for vascular ED. Results: We found significant differences in all the pairwise comparison of PSV in the $1 \mathrm{st}(0-5 \mathrm{~min}), 2 \mathrm{nd}$ (6-10 min), 3rd (11-15 min), and 4th (16-20 min) 4 intervals after the injection of prostaglandin E1 ( $<<0.001)$, except the 11-15 min vs. the 16-20 min interval ( $p=0.387$ ). Using cavernosography, 294 patients were diagnosed with venous ED. Compared with other intervals, the diagnosis of CDDU 11-15 min after the intracavernous injection of 20 ug prostaglandin E1 (PGE1) had the best consistency with cavernosography (Kappa $=0.761 ; \mathrm{p}<0.001)$. Compared with other intervals, CDDU at $11-15 \mathrm{~min}$ had the highest specificity (93.65\%), the highest Youden index (0.85), positive likelihood ratio of 14.46, positive predictive value of $98.54 \%$, negative predictive value of $71.08 \%$ and a coincidence rate of $92.16 \%$. Conclusions: Our findings support the increased utilization of CDDU for the diagnosis of both arterial and venous ED. The diagnosis at 11-15 min after intracavernous injection of PGE1 is accurate and stable, which would help to simplify the process and shorten the time of CDDU.
\end{abstract}

Keywords: color duplex Doppler ultrasound; erectile dysfunction; time-effect; cavernosography

\section{Introduction}

Erectile dysfunction (ED) is defined as the persistent inability to attain and maintain an erection sufficient to permit satisfactory sexual performance [1]. Epidemiological data have shown a high prevalence and incidence

Received 04.07.2019 Accepted 30.11.2019

Med Ultrason

2020, Vol. 22, No 1, 37-42

Corresponding author: Zhaohui Zhu

Department of Urology, Union Hospital,

Tongji Medical College, Huazhong University

of Science and Technology,

Wuhan 430022, China

E-mail:zhuzhaohui316@163.com

Phone: +8613807136996 of ED worldwide [2]. As a male sexual dysfunction, ED may affect physical and psychosocial health and may have a significant impact on the quality of life for sufferers and their partners. Moreover, ED can be the first presenting symptom of multi-organ endothelial dysfunction. The pathophysiology of ED may be vasculogenic, neurogenic, anatomical, hormonal, drug-induced and/or psychogenic [2].

Although phosphodiesterase-5 inhibitors (PDE5i) have been utilized as the first-line therapy for ED, in clinical practice $20-30 \%$ of patients with ED do not adequately respond to orally-administered PDE5i $[3,4]$. Objective vascular testing that provides a physiological diagnosis may help direct appropriate therapy [5]. Certain comorbidities associated with one or more risk 
factors may require further hemodynamic investigation, and in selected cases, this can be followed by an invasive penile angiographic evaluation [5]. Color duplex Doppler ultrasound (CDDU), first described by Lue et al [6], is an objective and reliable diagnostic method for documenting penile hemodynamics. CDDU of the penis can also help differentiate psychogenic from organic ED [5]. Veno-occlusive mechanisms and arterial insufficiency can be assessed using peak systolic velocity (PSV), enddiastolic volume (EDV) and spectral patterns on pulsed wave Doppler ultrasound examinations [7].

The lack of standardized measures often prevents the accurate clinical diagnosis of patients undergoing hemodynamic assessment of the penis using CDDU [5]. This also leads to variability in data interpretation when comparing the results among various centers. Sikka et al established standard operating procedures in 2012 and recorded data for arterial PSVs, EDVs, and resistance indices of the corpus cavernosum within $30 \mathrm{~min}$ after intracavernous injection (ICI) with prostaglandin E1 (PGE1) [5]. However, it is not clear which interval was the most suitable for diagnosis. Therefore, this study aimed to identify the optimal time interval for the diagnosis of ED after ICI, using CDDU.

\section{Materials and methods}

We employed a self-control study design. Because cavernosography is the most commonly used technique and can evaluate the venous occlusion function of the corpus cavernosum [8], we used the diagnostic capability of cavernosography as the gold standard to explore the time-effect of the CDDU. Informed consent was obtained from all participants and confidentiality was ensured. The study was approved by the local Ethics Committee.

\section{Subjects}

Patients with indication for CDDU and cavernosography were included in study if they 1) scored $<22$ on the 5-item version of the International Index of Erectile Function (IIEF-5) questionnaire thereby confirming ED; 2) could not take or failed to respond to PDE5i, which is required to determine the cause of the disease before treatment, or expected complete healing without the use of medicines; 3) did not suffer from neurogenic ED; 4) did not suffer from drug-induced ED; 5) did not suffer from hypertension, hyperlipidemia or liver and chronic kidney dysfunction; 6) did not suffer from severe psychological problems; 7) did not have an allergic reaction to the contrast medium (Ioversol); and 8) visited our clinic between June 2014 and March 2017.

Neurogenic ED was diagnosed by identifying a history of spinal cord lesions or pelvic surgery [9]. To evalu- ate the patients' psychological issues, we used a Chinese version of the Symptom Checklist-90 [10-12], a multidimensional symptom self-reporting inventory composed of 90 items, each rated on a 5-point scale of distress from 0 (not at all) to 4 (extremely) [13]. The global severity index (GSI) provided a summary score for the number and intensity of psychological distresses, and was determined by adding raw scores from all dimensions divided by the total number of items (90) [14]. If a patient's GSI was $>2$, he was referred to a psychologist and excluded from the study.

\section{CDDU}

With the patient in a supine position, a physician with 10 years' experience performed ICI of 20 ug PGE1 with a $27 \mathrm{G}$ needle [15].Dynamic CDDU was performed in all subjects by Philips IU22 machine using a linear transducer L12-5MHz. The sonographer gently lifted the patient's penis upwards toward the pubic symphysis, placed the probe at the crus of the penis and obtained an ultrasonographic B-mode image of the bilateral origin of the cavernous artery. The changes in arterial PSVs, EDVs and resistive indices in the $1 \mathrm{st}(0-5 \mathrm{~min}), 2 \mathrm{nd}(6-10 \mathrm{~min})$, 3rd (11-15 min), and 4th (16-20 min) intervals after PGE1 injection were recorded. The PSV was calculated as the mean PSV value of the left and right arteries in each patient. After pharmacological stimulation, the diagnosis of arterial ED was made if a PSV value of $<25$ $\mathrm{cm} / \mathrm{s}$ was obtained [7]. The diagnostic standard for venous ED using CDDU was considered PSV $\geq 25 \mathrm{~cm} / \mathrm{s}$, $\mathrm{EDV} \geq 5 \mathrm{~cm} / \mathrm{s}$ and $\mathrm{RI} \leq 0.8[16,17]$.

\section{Cavernosography}

After performing CDDU, patients underwent cavernosography within the next $72 \mathrm{~h}$. The nurse performed the puncture with a $24 \mathrm{G}$ needle in the left corpora cavernosum anterior coronary sulcus, $1-2 \mathrm{~cm}$ from the proximal segment at the back side of the 10-11 o'clock position of the penis. When the erection hardness score [18] attained 3, the nurse injected $320 \mathrm{mg} / \mathrm{ml}$ dilute loversol (30\%) into the penis at a rate of $30-60 \mathrm{ml} / \mathrm{min}$. An $\mathrm{X}$-ray cavernosograph using a Shimadzu Flexavision multi-function digital X-ray machine $(75 \mathrm{kv}, 4 \mathrm{mAs})$ was then performed on all patients with an erection hardness score of 4 . All procedures were conducted by a nurse and physician. All images were diagnosed by a physician according to the vascular anatomy of the penis [19].

\section{Assessment}

During CDDU, the changes in the arterial PSV, EDV, and RI at four different intervals: 0-5 min, 6-10 min, 11$15 \mathrm{~min}$, and 16-20 min after the injection of PGE1.The diagnoses obtained using cavernosography and CDDU at the different time intervals were compared. 


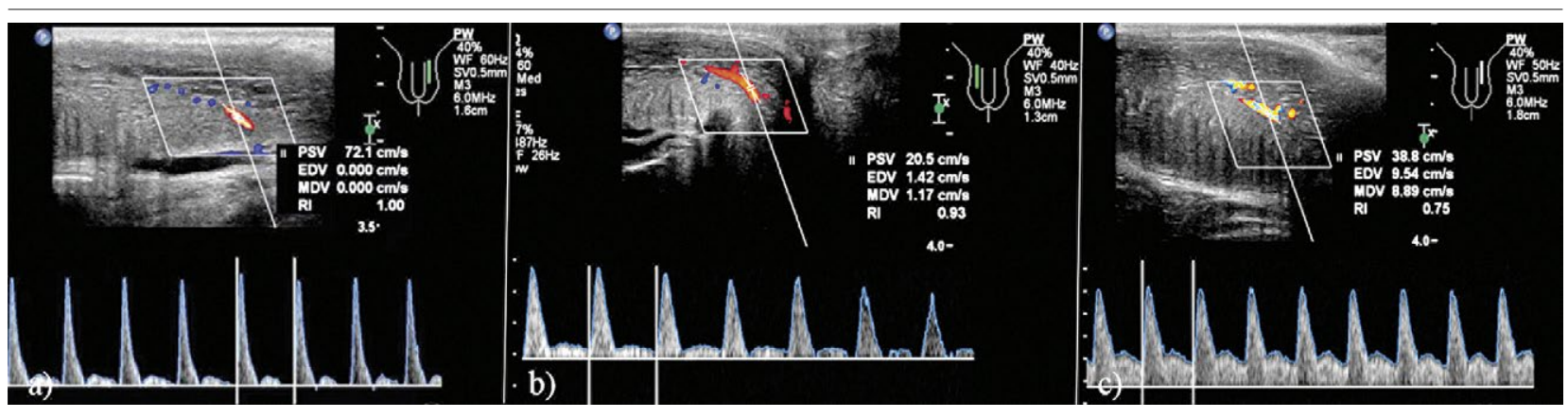

Fig 1. a). The normal image of a patient with PSV of $72.1 \mathrm{~cm} / \mathrm{s}$; b) The image of arterial ED with PSV of $20.5 \mathrm{~cm} / \mathrm{s}$; c) The image of venous ED with PSV of $38.8 \mathrm{~cm} / \mathrm{s}$, EDV of $9.54 \mathrm{~cm} / \mathrm{s}$ and RI of 0.75 .

\section{Statistical analysis}

We analyzed the data using the Statistical Package for the Social Sciences, Version 11.0 (SPSS, Chicago, IL). Quantitative data were expressed as the mean \pm standard deviation. We performed analysis of variance for univariate repeated measurement data to compare the PSVs among the four CDDU intervals. If statistical significance was found, we performed a Student-Newman-Keuls test for pairwise comparisons. The consistency between the two tests was assessed using Cohen's kappa coefficient and Youden index. The kappa value was interpreted as follows: over 0.75 , excellent; 0.40 to 0.75 ; fair to good, and below 0.40 ; poor [20]. $\mathrm{p}<0.05$ was considered to be statistically significant. The sensitivity (\%), specificity (\%), Youden index, positive and negative likelihood ratios, positive and negative predictive values (\%) and the coincidence rate (\%) of CDDU during the 4 intervals were also analyzed.

\section{Results}

In total, 372 patients were enrolled to undergo CDDU and cavernosography. Seven patients refused to undergo the tests and 8 patients were found to be allergic to loversol and were excluded. Finally, 357 patients with ED were included in the study. After undergoing CDDU and cavernosography, 10 patients $(2.8 \%)$ had foreskin hematomas, $3(0.8 \%)$ had priapism and $15(4.2 \%)$ experienced pain. In figure 1 are exemplified 3 different ED cases (normal CDDU parameters, venous and arterial ED).

The patient characteristics are detailed in Table I.

The means PSV in the 4 intervals were $19.3 \pm 3.5$ for $1-5 \mathrm{~min}, 24.9 \pm 3.7$ for $6-10 \mathrm{~min}, 31.2 \pm 5.1$ for $11-15 \mathrm{~min}$, and $30.5 \pm 4.8$ for $16-20 \mathrm{~min}$. There were significant differences in the PSVs values obtained in the 4 intervals $(p<0.001)$. Significant differences were also found in all pairwise comparisons of the 4 intervals $(p<0.001)$, with the exception of the $11-15 \mathrm{~min}$ vs. $16-20 \mathrm{~min}$ pairing $(\mathrm{p}=0.387)$ (Table II).
Table I. Baseline characteristic of included patients

\begin{tabular}{ll}
\hline Characteristic & \\
\hline Age (years) & $31.05 \pm 6.37$ \\
Course of disease (years) & $4.16 \pm 1.34$ \\
Marriage age (years) & $6.35 \pm 5.53$ \\
Smoking history & $282(79)$ \\
Drinking history & $277(77.6)$ \\
Scores of IIEF-5 & $11.21 \pm 5.59$ \\
GSI of SCL-90 & $0.63 \pm 0.47$ \\
Time for penis began erection (min) & $3.51 \pm 1.62$ \\
Time to reach maximum erection (min) & $11.23 \pm 1.14$ \\
\hline
\end{tabular}

The results are expressed as mean \pm standard deviation or number (\%). IIEF-5, 5-item version of the International Index of Erectile Function; SCL-90, Symptom Checklist 90; GSI, Global severity index.

Table II. Comparison of PSV between the four intervals in color duplex Doppler ultrasound (Student-Newman-Keuls)

\begin{tabular}{llll}
\hline & $\begin{array}{l}\text { Mean } \\
\text { difference }\end{array}$ & q & p \\
\hline 1-5 min vs. 6-10 min & 5.6 & 12.39 & $<0.001$ \\
1-5 min vs. 11-15 min & 11.9 & 30.23 & $<0.001$ \\
1-5 min vs. 16-20 min & 11.2 & 29.31 & $<0.001$ \\
6-10 min vs. 11-15 min & 5.3 & 11.27 & $<0.001$ \\
6-10 min 1 vs. 16-20 min & 5.6 & 12.39 & $<0.001$ \\
11-15 min vs. 16-20 min & -0.7 & 1.67 & 0.387 \\
\hline
\end{tabular}

As shown in Table III, 82.4\% (284/357) of patients had venous ED. The agreement between 6-10 min interval and 11-15 min interval was good. Table IV shows detailed CDDU performances in all 4 intervals. Compared with the other intervals, CDDU at 11-15 min after ICI had the highest specificity (93.65\%), Youden index (0.85), positive likelihood ratio (14.46), positive predictive value $(98.54 \%)$, negative predictive value $(71.08 \%)$, and coincidence rate $(92.16 \%)$. 
Jin Wang, Jing Wang et al Time-effect of penile color duplex Doppler ultrasound for diagnosing vascular erectile dysfunction

Table III. Diagnosis of ED with color duplex Doppler ultrasound (CDDU) and cavernosography in 4 intervals

\begin{tabular}{|c|c|c|c|c|c|}
\hline \multirow{2}{*}{ CDDU } & & \multicolumn{2}{|c|}{ Cavernosography } & \multirow[t]{2}{*}{ Kappa } & \multirow[t]{2}{*}{$\mathbf{P}$} \\
\hline & & + & - & & \\
\hline \multirow[t]{2}{*}{$1-5 \mathrm{~min}$} & + & 282 & 56 & 0.097 & 0.024 \\
\hline & - & 12 & 7 & & \\
\hline \multirow[t]{2}{*}{$6-10 \mathrm{~min}$} & + & 277 & 22 & 0.612 & $<0.001$ \\
\hline & - & 17 & 41 & & \\
\hline \multirow[t]{2}{*}{$11-15 \min$} & + & 270 & 4 & 0.761 & $<0.001$ \\
\hline & - & 24 & 59 & & \\
\hline \multirow[t]{2}{*}{$16-20 \mathrm{~min}$} & + & 269 & 19 & 0.591 & $<0.001$ \\
\hline & - & 25 & 44 & & \\
\hline
\end{tabular}

Table IV. Comparison of diagnostic effectiveness of color duplex Doppler ultrasound in four intervals

\begin{tabular}{lllll}
\hline & $\mathbf{1 - 5}$ min & $\mathbf{6 - 1 0}$ min & $\mathbf{1 1 - 1 5}$ min & $\mathbf{1 6 - 2 0}$ min \\
\hline Sensitivity (\%) & 95.92 & 94.22 & 91.84 & 91.50 \\
Specificity (\%) & 11.11 & 65.08 & 93.65 & 69.84 \\
Youden index & 0.07 & 0.59 & 0.85 & 0.61 \\
Positive likelihood ratio & 1.08 & 2.70 & 14.46 & 3.03 \\
Negative likelihood ratio & 0.38 & 0.09 & 0.09 & 0.12 \\
Positive predictive value (\%) & 83.43 & 92.64 & 98.54 & 93.40 \\
Negative predictive value (\%) & 36.84 & 70.69 & 71.08 & 63.77 \\
Coincidence rate (\%) & 80.95 & 89.08 & 92.16 & 87.68 \\
\hline
\end{tabular}

\section{Discussion}

For the correct diagnosis of vascular ED, CDDU is a useful and simple tool for differentiating organic from psychological causes. As far as we know, this is the first study to demonstrate the time-effect of CDDU in the diagnosis of vascular ED.

In the present study, the mean age of the included patients was $31.05 \pm 6.37$ years, which implies that most patients with vascular ED are young Chinese adults. Similarly, in a cross-sectional real-life study among men seeking initial medical help for new-onset ED, one in four patients were younger than 40 years, with almost $50 \%$ of the young men complaining of severe ED [21]. Our results showed that PSVs become stable 11-20 min after ICI, which is the best time interval for diagnosing arterial ED using CDDU.

Cavernosography revealed a high rate $(82.4 \%)$ of venous ED among the included patients, which is similar to the rate reported in a previous study conducted by Yafi et al [22]. For the diagnostic conformance of venous ED using cavernosography and CDDU, the 11-15 min interval after ICI had the highest Kappa value (0.761), representing excellent agreement. We found that all interval sensitivities were $>90$. Moreover, the 6-10 and 11-15 min intervals also had the lowest negative likelihood ratio (0.09). Compared to other intervals, CDDU at 11-15 min after ICI had the highest specificity and the best coincidence. Because the pressure inside the corpus caverno- sum is small, EDVs more than $5 \mathrm{~cm} / \mathrm{s}$ in $1-5 \mathrm{~min}$ lead to higher sensitivities for venous ED. However, at the same time, the possibility of false positives is high. Thus, the CDDU results indicated that the highest accuracy is attained for CDDU performed 11-15 min after ICI.

However, it is noteworthy to mention that the venoocclusive mechanism may not function properly in some patients with arterial insufficiency thereby decreasing the intracavernous pressure and preventing closure of the emissary connections [7]. Kropman et al reported that many patients present with combined arterial and venous ED. In the subset of patients with significant arterial ED, the specificity of EDV correlated with pathologic venous ED significantly decreases [23].

Cavernosography uses radiological imaging to both diagnose and locate the sites of venous leaks in patients. However, because of its invasiveness, its utility is limited [24]. For this reason, in our opinion, CDDU following ICI with a vasodilator agent remains the most reliable and the least invasive test for the determination of the etiology of ED being a minimally invasive and accurate method for evaluating penile hemodynamics [17]. Caversonometry, caversonography of cavernous bodies and selective pudental arteriography are advanced and rather invasive diagnostic tests that should be reserved for cases that cannot be definitively diagnosed using CDDU $[7,25]$.

For patients with ED who cannot take PDE5i or fail to respond to PDE5i, in which the cause of the disease 
must be determining before treatment, or for those patients who expect complete healing without the use of medicines, CDDU after ICI is recommended for further diagnostic confirmations and prognosis determinations. Our findings of time-effects while using CDDU in the diagnosis of both arterial and venous ED could make CDDU more convenient and accurate. It would help to avoid unnecessary waiting, improve its accuracy and be convenient for both medical staff and patients.

\section{Strengths and limitations}

Our study had some strengths. First, all included patients had undergone both CDDU and cavernosography assessments and it was a self-control design. Second, we provided a large sample size of patients with ED who either could not take PDE5i or failed to respond to PDE5i, or expected complete healing without the use of medicines. The findings of our study should also be noted in light of the following limitations. First, penile measurements might be affected by multiple factors including the degree of penile tumescence or rigidity, penile curvature, subjective variability in stretching and operator technique, although a single experienced physician performed all measurements. Second, single center data may lead to Berkson's bias and has an impact on its external validation. Third, the majority of our included subjects were young adults, which restricted the extrapolation of this study. Finally, while we used the cavernosography results as the standard for venous CDDU, false positive and negative results could occur.

\section{Conclusion}

Our findings demonstrated that CCDU is effective for the correct diagnosis of ED and support the increased utilization of CDDU for the diagnosis of both arterial and venous ED. A diagnosis of ED 11-15 min after ICI is accurate and stable which helps to simplify the process and shorten the CDDU time. Further studies are required to confirm the time-effect of CDDU in the diagnosis of vascular ED.

\section{Conflict of interest: none}

Acknowledgment: This work was supported by the National Natural Science Foundation of China (No.81771851).

\section{References}

1. NIH Consensus Conference. Impotence. NIH Consensus Development Panel on Impotence. JAMA 1993;270:83-90.
2. European Association of Urology Guidelines. 2017 edition. 2017. Available at: https://uroweb.org/guidelines/.

3. Caretta N, Palego PA, Roverato A, Selice R, Ferlin A, Foresta C. Age-matched cavernous peak systolic velocity: a highly sensitive parameter in the diagnosis of arteriogenic erectile dysfunction. Int J Impot Res 2006;18:306-310.

4. Meuleman EJ, Hatzichristou D, Rosen RC, Sadovsky R. Diagnostic tests for male erectile dysfunction revisited. Committee Consensus Report of the International Consultation in Sexual Medicine. J Sex Med 2010;7:2375-2381.

5. Chen L, Xu L, Wang J, et al. Diagnostic Accuracy of Different Criteria of Pharmaco-penile DuplexSonography for Venous Erectile Dysfunction. J Ultrasound Med 2019;38:2739-2748.

6. Altinbas NK, Hamidi N. Penile Doppler ultrasonography and elastography evaluation in patients with erectile dysfunction. Pol J Radiol 2018;83:e491-e499.

7. Yildirim D, Bozkurt IH, Gurses B, Cirakoglu A. A new parameter in the diagnosis of vascular erectile dysfunction with penile Doppler ultrasound: cavernous artery ondulation index. Eur Rev Med Pharmacol Sci 2013;17:13821388.

8. Glina S, Ghanem H. SOP: corpus cavernosum assessment (cavernosography/cavernosometry). J Sex Med 2013;10:111-114.

9. Lombardi G, Musco S, Kessler TM, Li Marzi V, Lanciotti M, Del Popolo G. Management of sexual dysfunction due to central nervous system disorders: a systematic review. BJU Int 2015;115 Suppl 6:47-56.

10. Sereda Y, Dembitskyi S. Validity assessment of the symptom checklist SCL-90-R and shortened versions for the general population in Ukraine. BMC Psychiatry 2016;16:300.

11. Roberts N, Parker KC, Dagnone M. Comparison of Clinical Diagnoses, NIMH-DISC-IV Diagnoses and SCL-90-R Ratings in an Adolescent Psychiatric Inpatient Unit: A Brief Report. Can Child Adolesc Psychiatr Rev 2005;14:103105.

12. Chen S, Peng D, Xu X, et al. Assessment of erectile dysfunction and associated psychological distress in Chinese men with type 2 diabetes mellitus. Int J Impot Res 2017;29:210-214.

13. Barbonetti A, Cavallo F, Felzani G, Francavilla S, Francavilla F. Erectile Dysfunction is the Main Determinant of Psychological Distress in Men with Spinal Cord Injury. J Sex Med 2012;9:830-836.

14. Aghighi A, Grigoryan VH, Delavar A. Psychological determinants of erectile dysfunction among middle-aged men. Int J Impot Res 2015;27:63-68.

15. Speel TG, Van Langen H, Wijkstra H, Meuleman EJ. Penile duplex pharmaco-ultrasonography revisited: revalidation of the parameters of the cavernous arterial response. J Urol 2003; 169:216-220.

16. Aversa A, Bruzziches R, Spera G. Diagnosing Erectile Dysfunction: The penile dynamic colour duplex ultrasound revisited. Int J Androl 2005;28(Supplement 2):61-63.

17. Chen L, Hu B, Feng C, Sun XJ. Predictive value of penile dynamic colour duplex Doppler ultrasound parameters in 
patients with posttraumatic urethral stricture. J INT MED RES 2011;39:1513-1519.

18. Matsuda Y, Hisasue S, Kumamoto Y, et al. Correlation between erection hardness score and nocturnal penile tumescence measurement. J Sex Med 2014;11:2272-2276.

19. Uflacker R. Atlas of vascular anatomy: An angiographic approach. Second edn: Lippincott Williams \& Wilkins; 2006.

20. Fleiss JL. Statistical methods for rates and proportions. Technometrics 2003;16:326-327.

21. Capogrosso P, Colicchia M, Ventimiglia E, et al. One patient out of four with newly diagnosed erectile dysfunction is a young man--worrisome picture from the everyday clinical practice. J Sex Med 2013;10:1833-1841.

22. Yafi FA, Libby RP, Mccaslin IR, Sangkum P, Sikka SC, Hellstrom WJG. Failure to attain stretched penile length after intracavernosal injection of a vasodilator agent is predictive of veno-occlusive dysfunction on penile duplex Doppler ultrasonography. Andrology 2015;3:919-923.

23. Kropman RF, Schipper J, van Oostayen JA, Lycklama à Nijeholt AA, Meinhardt W. The value of increased end diastolic velocity during penile duplex sonography in relation to pathological venous leakage in erectile dysfunction. J Urol 1992;148:314-317.

24. Hatzichristou DG, Saenz de Tejada I, Kupferman S, et al. In vivo assessment of trabecular smooth muscle tone, its application in pharmaco-cavernosometry and analysis of intracavernous pressure determinants. J Urol 1995;153:11261135 .

25. Kawanishi Y, Muguruma H, Kusuhara Y, et al. MP-07.10 3D Cavernosography and Virtual Cavernoscopy with Low Pressure Dynamic Infusion Cavernosometry and Cavernosography. Urology 2011;78(Suppl 3A):S79. 